\title{
Graphene/Cu composites: Electronic and mechanical properties by first- principles calculation
}

\author{
Qian Zhang, ${ }^{\mathrm{a}, \mathrm{b}}$, Ying Liư ${ }^{\mathrm{a}, \mathrm{b}}$, Ting Liao ${ }^{\mathrm{c}}$, Caili Zhang ${ }^{\mathrm{a}, \mathrm{b}}$, Xiaolei Wu $\mathrm{W}^{\mathrm{d}}$, Yongsheng Liu ${ }^{\mathrm{a}, \mathrm{b}}$, \\ Muhammad Saqlain Qurashi ${ }^{\mathrm{a}, \mathrm{b}}$, Feng Zheng ${ }^{\mathrm{a}, \mathrm{b}}$, Qingsong Song ${ }^{\mathrm{a}, \mathrm{b}}$, Peide Han ${ }^{\mathrm{a}, \mathrm{b}, *}$ \\ ${ }^{a}$ College of Materials Science and Engineering, Taiyuan University of Technology, Taiyuan, 030024, China \\ ${ }^{\mathrm{b}}$ Key Laboratory of Interface Science and Engineering in Advanced Materials, Taiyuan University of Technology, Taiyuan, 030024, China \\ ${ }^{\mathrm{c}}$ School of Chemistry, Physics and Mechanical Engineering, Queensland University of Technology, Brisbane, QLD, 4000, Australia \\ ${ }^{\mathrm{d}}$ State Key Laboratory of Nonlinear Mechanics, Institute of Mechanics, Chinese Academy of Sciences, Beijing, 100190, China
}

\section{H I G H L I G H T S}

- Deformation mechanism of graphene/ $\mathrm{Cu}$ composite materials was systematically summarized.

- Graphene/Cu systems present an excellent electrical conductivity and increasing Debye temperature compared with pure $\mathrm{Cu}$.

- Compared to copper, the tensile strength of graphene/Cu composites are enhanced by $174 \%$ and $162 \%$ in parallel to the direction of graphene.

- Strengthening and toughening effects of graphene in composites is originated from strain strengthening and load transfer.

\section{A R T I C L E I N F O}

\section{Keywords:}

Graphene

First principles

Physical properties

Mechanical properties

Deformation mechanism
G R A P H I C A L A B S T R A C T

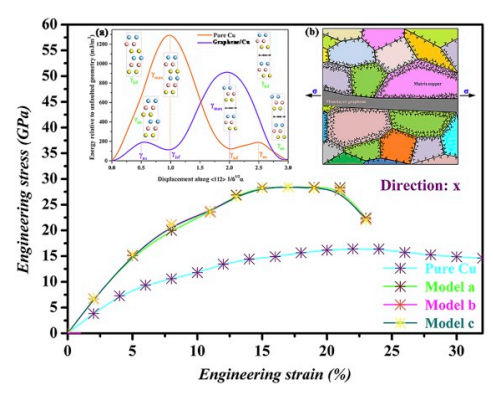

\begin{abstract}
A B S T R A C T
Graphene characterized with ultrahigh intrinsic strength and excellent electronic properties is an ideal material to reinforce metals without despairing their thermal and electrical properties. Here, the electronic and mechanical properties of graphene intercalated copper (graphene/Cu) composites are investigated using density functional theory calculations. Graphene/Cu systems present an excellent electrical conductivity and increasing Debye temperature from $335 \mathrm{~K}$ for pure $\mathrm{Cu}$ to over $535 \mathrm{~K}$ in regardless of stacking models. In addition to greatly enhanced Young's modulus (149\%), shear modulus (156\%) and bulk modulus (108\%) compared to copper, the ultimate strength of graphene/Cu composites are enhanced by $174 \%$ and $162 \%$, in $\mathrm{x}$ and y directions, respectively. The strengthening and toughening effects of graphene in the composites is originated from strain strengthening and load transfer, which is consistent with the experimental results. Based on this calculation, the strengthening mechanism can be understood, which explains many experimental observations and also provides us a guide to improve graphene/metal composites quality.
\end{abstract}

\footnotetext{
${ }^{*}$ Corresponding author. College of Materials Science and Engineering, Taiyuan University of Technology, 030024, Taiyuan, China.

E-mail address: hanpeide@tyut.edu.cn (P. Han).
} 


\section{Introduction}

Copper $(\mathrm{Cu})$ is one of the most extensively used material due to its high electrical and thermal conductivities combined with environmentfriendly and easy available material with good corrosion resistance. Thanks to these excellent properties, $\mathrm{Cu}$ has wide variety of applications, such as in integrated circuit, electrical conductors, radiators, and electrodes and so on $[1,2]$. As a result of its poor mechanical properties, $\mathrm{Cu}$ is not considered as a good material for structural applications, which has greatly limited its application. Recently, scientists and engineers have developed various strategies to get rid of weak mechanical properties without deterioration of original physical properties, such as metal matrix composites, nanolaminated structure, and nano-twinned structure, gradient structure, multi- and bimodal microstructures [3-6]. Among which, introducing graphene reinforcement is an effective method to obtain a $\mathrm{Cu}$ matrix composite with stable structural and outstanding functional performances. Recently, graphene has aroused considerable interest around the world due to its superior mechanical properties and stiffness, excellent thermal properties and low weight [7-10]. Several experimental investigations demonstrated that graphene-reinforced metal composites have higher strengths, better electrical conductivity and thermal conductivity in combination with lighter weights, compared with conventional metals and composites [11-14].

In order to meet the constantly increasing demands for structural strength and energy efficiency, graphene reinforced $\mathrm{Cu}$ matrix composites were analyzed through some experimental investigations. The results revealed that adding a small amount of graphene resulted in valuable improvements in the mechanical properties of $\mathrm{Cu}$ matrix. For example, according to Wang et al. [13] by means of reducing the graphene oxide fabricated then spark plasma sintering at $600^{\circ} \mathrm{C}$ for $5 \mathrm{~min}$ with an applied pressure of $40 \mathrm{MPa}$ synthesis of graphene-copper composites within the micro-layered grains, which results showed that the graphene not only improved the strength greatly, but also improved the conductivity by adding $2.5 \%$ volume of graphene oxide. Jiang et al. [14] used simple slurry based process and powder metallurgy at $30 \mathrm{MPa}$ and $973 \mathrm{~K}$ for $5 \mathrm{~min}$ to fabricate bulk graphene/Cu composite, yield strength was up to $172 \mathrm{MPa}$, which was $90 \%$ higher than pure Cu with adding $0.3 \mathrm{wt} \%$ of graphene to matrix. Additionally, Chen et al. [15] through a graphene in-situ grown approach, which involved ball-milling of $\mathrm{Cu}$ powders with PMMA as solid carbon source, in-situ growth of graphene on flaky $\mathrm{Cu}$ powders and vacuum hot-press sintering fabricated copper composite with $0.95 \mathrm{wt} \%$ graphene with a noticeable increase in yield strength of $244 \mathrm{MPa}$, which was $177 \%$ enhancement. As a two-dimension lamellar material, graphene has unique deformation mechanism. Yet, the strengthening mechanism of graphene is confined to second-phase strengthening [16,17]. To optimize strength and toughness, it is highly required to understand the underlying atomic details of strengthening mechanism. Unfortunately, at the atomic scale, our knowledge regarding the interaction mechanism between single layer graphene and copper is still very limited. For example, even the most fundamental question, "what is the deformation mechanism of composites?" is still unclear.

A few atomistic simulations were also carried out to investigate the role of graphene in improving the mechanical properties of composites. Duan et al. and He et al. conducted a series of molecular dynamics simulations to examine the tensile behavior of graphene-embedded copper nanocomposites $[18,19]$. It was found that the graphene-embedded copper has better Young's modulus, tensile strength and fracture strength in comparison with pure $\mathrm{Cu}$, which attributed to inherent axial stiffness of graphene and considerable interface slip stresses. Using a similar method, shear strength and toughness of graphene copper nanolayered composites were investigated by Liu et al. [20]. Their findings indicated that interfacial constraining effect between graphene and copper layer play an important role in improving the shear strength and the toughness of nanolayered composites. Comprehensively it can be known that although the graphene have a remarkable effect on copper matrix composites, the simulation of deformation mechanism of these composites is only limited to the nanoscale. The deformation mechanism of composites in atomic level remains undefined, and the mechanism of interaction between atoms is not very distinct. Here, we use first-principles to simulate the tensile process of composites, hoping for more detailed analyses to reveal the strengthening mechanism of graphene in composites and understand the deformation mechanism of $\mathrm{Cu}(111) /$ graphene/Cu(111) (graphene/Cu) composites at the atomicscales.

This paper is organized as follows. Section 2 deals with the computational methods. Optimized geometric structure models are described in Sec. 3.1. In Sec. 3.2 we carried out the analysis of energies, structure and interface stability models. Section 3.3 contrasts physical properties of composites and pure copper. In Sec. 3.4 we performed tensile simulation and study their mechanical stability. In Sec. 3.5, deformation mechanism of composites is discussed by means of change of magnitude of atomic charge, displacement change of atoms and generalized stacking fault energies curves. Finally, Section 4 concludes with a summary.

\section{Computational methods}

First-principles calculations are performed based on pseudopotential and plane-wave basis, set within the density functional theory (DFT) using the Cambridge Serial Total Energy Package (CASTEP) software. We used the generalized gradient approximation (GGA) with the Perdew-Burke-Ernzerhof parametrization (GGA-PBE) for exchangecorrelation function [21,22]. A plane-wave cut-off kinetic energy was taken as $340 \mathrm{eV}$. During geometry optimization, the Brillouin zone sampling was carried out with a $5 \times 5 \times 1$ Monkhorst-Pack k-point grid. To obtain the correct calculation results, we employed the DFT-D method proposed by Grimme [23] to account the long-range van der Waals interactions and optimized the coordinates of all atoms in the slab and the lattice parameters (a, b, c, $\alpha, \beta$ and $\gamma$ ). The models calculations were followed by cell optimization with an energy convergence tolerance of $1.0 \times 10^{-5} \mathrm{eV} /$ atom, a maximum displacement of $0.001 \AA$, and maximum force of $0.03 \mathrm{eV} / \AA$.

The results presented in this work are obtained using a $2 \times 2$ supercell for pure copper, having 24 copper atoms and graphene/copper systems with 24 copper atoms and 8 carbon atoms in graphene layer. The composites models are composed by monolayer graphene, and six atomic layers of copper, and the stacking way about three layers of copper atoms upper graphene is exactly same with copper atoms under graphene. The mismatch between $\mathrm{Cu}(111)$ 's surface lattice constant of $2.56 \AA$ and graphene's lattice constant of $2.46 \AA$ is $3.8 \%$. The experimental results show that $60 \%$ of graphene grains incline to rotate by $3^{\circ}$ with respect to the substrate $\mathrm{Cu}(111)$ [24]. In order to account for the lattice mismatch [25] and to describe graphene as realistically as possible [26], the simulation cell in-plane dimensions chosen the experimental graphene lattice constant, then adapting the lattice constant of copper accordingly.

To validate the accuracy of the current theoretical scheme, the crystal lattice constants of the composites were calculated to be $\mathrm{a}=\mathrm{b}=2.49 \AA$, which is in good agreement with the calculated graphene's lattice constant of $2.46 \AA$ [25], the C-C bond length was calculated to be $1.435 \AA$ on graphene/copper systems, which is in good agreement with the calculated value of $1.425 \AA$ [9]. The interlayer distances between graphene and $\mathrm{Cu}(111)$ are also in good agreement with previous investigation $[27,28]$. These validate the application of the methodology to study physical and mechanical properties. 


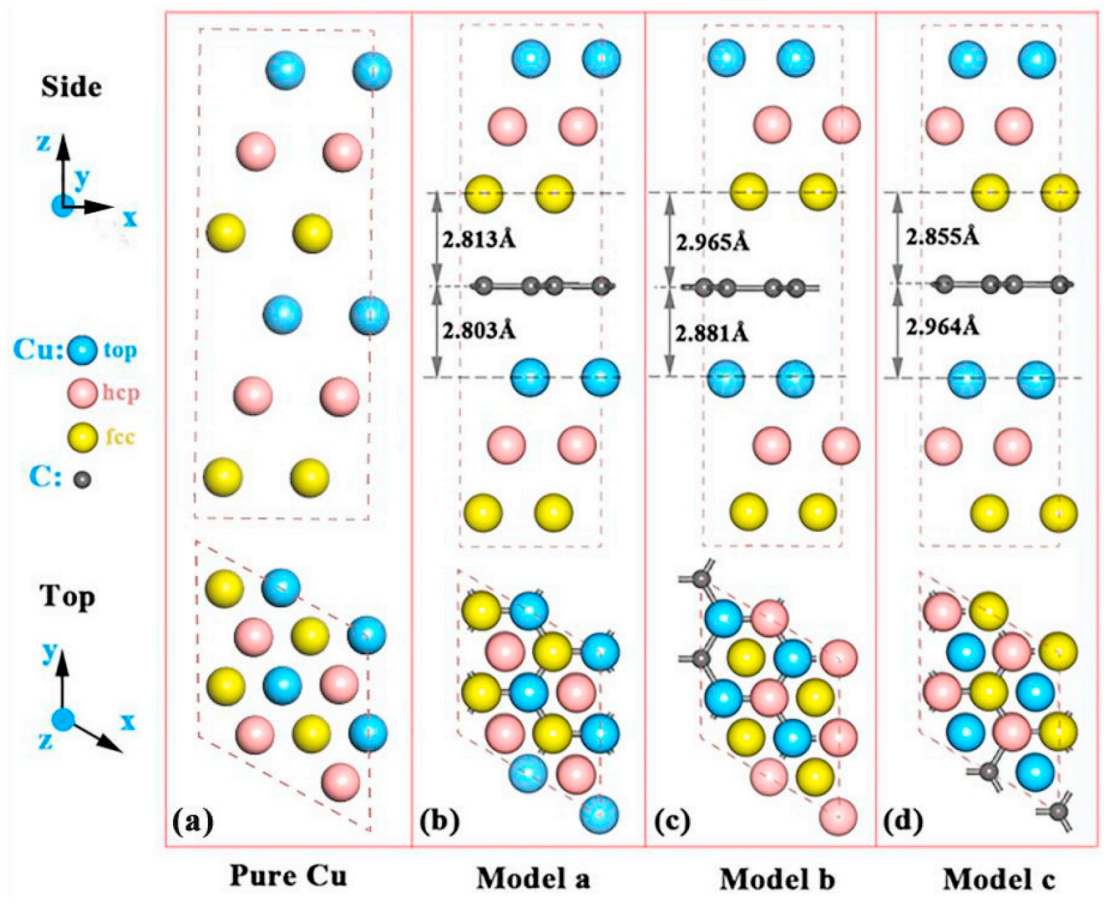

Fig. 1. Top and side view of pure $\mathrm{Cu}$, model a (top-fcc), model b (top-hcp) and model c (fcc-hcp). Blue, pink and yellow (large) spheres indicate the copper atoms, black (small) spheres are the carbon atoms. The copper layers are labeled by top, hcp, and fcc (top, hcp, and fcc layers coppers expressed in blue, pink and yellow respectively). (For interpretation of the references to colour in this figure legend, the reader is referred to the Web version of this article.)

\section{Result and discussion}

\subsection{Geometric structure}

In the vertical direction of the $\mathrm{Cu}(111)$ one distinguishes three nonequivalent $\mathrm{Cu}$ planes/layers, we name the copper layers as top, hcp and fcc, as shown in Fig. 1 (top, hcp and fcc layers of coppers expressed in blue, pink and yellow respectively). According to which carbon atoms sit over in copper layer, we test three different commensurate configurations, which could give rise to three possible graphene physisorbed positions named as top-fcc (model a), top-hcp (model b), and fcc-hcp (model c) configurations [25]. Fig. 1(a, b, c and d) show the side and top views of the pure $\mathrm{Cu}$ and three geometric structures. As shown in Fig. 1(b), in top-fcc (model a), where one carbon atom is on top of a copper atom of the top layer, while another nonequivalent carbon is over the fcc $\mathrm{Cu}$ layer. For top-hcp (model b), the two nonequivalent carbon atoms are above on the top or hcp Cu layer. Similarly to fcc-hcp (model c) configuration, the two nonequivalent carbon atoms are situated above the $\mathrm{Cu}$ atoms of the hcp and fcc sites. Moreover, top view can be seen that yellow, blue copper atoms and graphene make up the interfaces of composites.

After optimizing those models, the distances between graphene and adjacent copper atomic layers are $2.813 \AA / 2.803 \AA$, $2.965 \AA / 2.881 \AA$, $2.855 / 2.964 \AA$ for model a, model b and model c as shown in Fig. 1 b, c and $\mathrm{d}$, respectively.

\subsection{Energies, structure and interface stability}

To examine the structure stabilities of different models, the binding energies $\left(E_{\mathrm{b}}\right)[29]$ are calculated based on the following formulas:

$E_{\mathrm{b}}=\frac{1}{\mathrm{~m}+\mathrm{n}}\left(E_{\text {total }}-m E_{\text {iso }}^{\mathrm{Cu}}-n E_{\text {iso }}^{\mathrm{C}}\right)$

where $E_{\text {total }}$ is the total energy of the bulk model, $\mathrm{m}$ and $\mathrm{n}$ represents copper atoms and carbon atoms in graphene respectively. Based on the computation models, we know $m=24, n=8 ; E_{\text {iso }}^{\mathrm{Cu}}$ and $E_{\text {iso }}^{\mathrm{C}}$ are energies of the isolated copper atom and carbon atom in graphene.

In the case of composite materials, especially in mechanical performance, the interface plays a decisive role. Interfacial energy $\left(E_{i \mathrm{~b}}\right)$ and interfacial separation work $\left(W_{\text {sep }}\right)$ properties between graphene and
$\mathrm{Cu}(111)$ are calculated as [30]:

$E_{i \mathrm{~b}}=E_{\mathrm{GR}}+E_{\mathrm{slab}}^{\mathrm{Cu}}-E_{\mathrm{total}}$

where is the total energy of the graphene/copper interface structure; $E_{G R}$ is total energy of monolayer graphene with 8 carbon atoms. $E_{\text {slab }}^{\mathrm{Cu}}$ is the six-layer reference $\mathrm{Cu}$ slab with interface areas.

$W_{\text {sep }}=\left(E_{1}^{\text {tot }}+E_{2}^{\text {tot }}-E_{12}^{\text {tot }}\right) / \mathrm{S}$

where $E_{\mathrm{i}}^{\text {tot }}$ is the total energy of separated slab i; $E_{12}^{\text {tot }}$ is the total energy of whole system, and $S$ is the total interfacial area of the unit cell. As shown in Fig. 1, Model b, c and d all have two interfaces, the upper named $W_{\text {sep }}^{\text {upper }}$, the lower named $W_{\text {sep }}^{\text {lower }}$.

The calculated values of $E_{b}, E_{\mathrm{ib}}, \mathrm{W}_{\text {sep }}^{\text {upper }}$ and $\mathrm{W}_{\text {sep }}^{\text {lower }}$ of three different configurations are shown in Table 1. Table 1 tells us in three models $E_{b}$, $\mathrm{E}_{\mathrm{ib}}$ and $\mathrm{W}_{\text {sep }}$ all have a very small difference. The absolute values of $\mathrm{E}_{\mathrm{b}}$ indicates that model $a$ is the most stable configuration with $E_{b}$ of $-2.946 \mathrm{eV}$ per atom; on the contrary, model $\mathrm{c}$ is the most unstable structure with $E_{b}$ of $-2.943 \mathrm{eV}$. The interface energy $E_{i b}$ is also called the interface formation energy, the greater the value, the more stable the interface. Analysis of interface energy $E_{i b}$ indicates that interfacial stability follows the order like model a $(10.12 \mathrm{eV})>$ model $b$ $(10.04 \mathrm{eV})>$ model $\mathrm{c}(10.03 \mathrm{eV}) . \mathrm{W}_{\text {sep }}$ is closely related to the layer distances and the atomic bonding at the interface [29]. The greater the separation work, the smaller the interval between the layers. The layer distance of model a is the smallest, indicating that the adhesion of the interface is the strongest, whose values of $\mathrm{W}_{\text {sep }}^{\text {upper }}$ and $\mathrm{W}_{\text {sep }}^{\text {lower }}$ are almost equal, the interlayer of the upper and lower copper atoms while graphene in the middle are nearly same. This change of law also applies to model $\mathrm{b}$ and model c. Table 1 indicates that energies, structure and interface stability among model a, model b and model $\mathrm{c}$ have a little difference, which result in their electrical conductivity, Debye

Table 1

$\mathrm{E}_{\mathrm{b}}\left(\mathrm{eV}\right.$ per atom), $\mathrm{E}_{\mathrm{ib}}(\mathrm{eV})$ and $\mathrm{W}_{\mathrm{sep}}\left(\mathrm{J} / \mathrm{m}^{2}\right)$ of different models.

\begin{tabular}{lllll}
\hline Construction & $\mathrm{E}_{\mathrm{b}}$ & $\mathrm{E}_{\mathrm{ib}}$ & $\mathrm{W}_{\text {sep }}^{\text {upper }}$ & $\mathrm{W}_{\text {sep }}^{\text {lower }}$ \\
\hline Model a & -2.946 & 10.12 & 6.03 & 6.03 \\
Model b & -2.944 & 10.04 & 5.99 & 6.03 \\
Model c & -2.943 & 10.03 & 6.01 & 5.99 \\
\hline
\end{tabular}



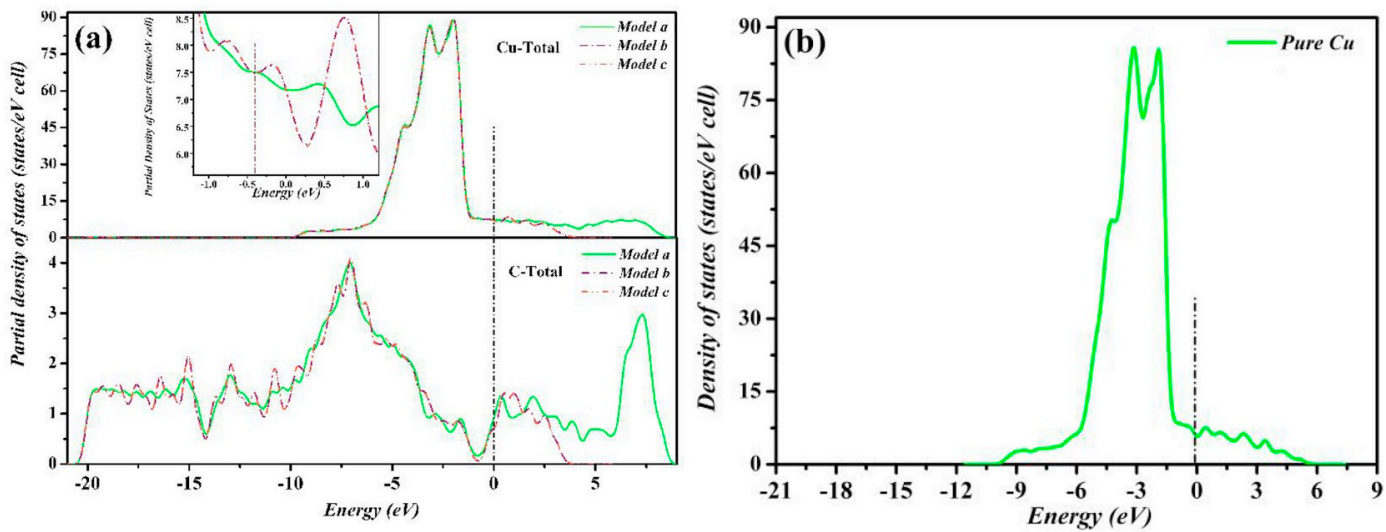

Fig. 2. (a) PDOS of atom $\mathrm{Cu}$ and $\mathrm{C}$ in $\mathrm{Cu}$ /graphene composites; (b) DOS for pure $\mathrm{Cu}$.

temperature and tensile properties mentioned below having a tiny discrepancy.

\subsection{Physical properties}

\subsubsection{Electrical conductivity}

According to Boltzmann transport equation and Einstein relation, electrical conductivity is proportional to density of states [31]. As shown in Fig. 2(a), at the Fermi level $\left(E_{F}\right)$, the numeric values of total density of states for copper atoms in model a, b and c are 7.18, 7.18 and 7.17 states per unit cell per eV, respectively. However, the numeric value of total density of states of pure copper is 5.82 states per unit cell per eV, as shown in Fig. 2(b). Hence one can conclude that the addition of graphene promotes the conductivity of copper matrix [32].

\subsubsection{Debye temperature}

Debye temperature is a fundamental parameter for crystals, closely related to many physical properties of bulk materials, such as specific heat, thermal conductivity, melting temperature and so on, also closely bounded up with structural stability and the strength of bonds of the solids. It can be estimated by the average sound velocity $\left(\nu_{m}\right)$ [33].

$\Theta_{D}=\frac{h}{K_{B}}\left(\frac{3 n}{4 \pi V_{a}}\right)^{1 / 3} \nu_{m}$

Where $h$ is the Plank's constant, $K_{B}$ is the Boltzmann's constant, $n$ is the number of atoms in cell and $V_{a}$ is the cell volume. The average sound velocity can be calculated in terms of the longitudinal $\left(\nu_{l}\right)$ and transverse $\left(v_{t}\right)$ elastic wave velocity as $[33,34]$.

$v_{m}=\left[\frac{1}{3}\left(\frac{1}{v_{l}^{3}}+\frac{2}{v_{t}^{3}}\right)\right]^{-1 / 3}$

$v_{\iota}=\left(\frac{3 B+4 G}{3 \rho}\right)^{1 / 2}$

$v_{t}=\left(\frac{G}{\rho}\right)^{1 / 2}$

Where $\rho$ represents the density of materials; $v_{\iota}$ and $v_{t}$ is the longitudinal and transverse sound velocity, which are obtained by the bulk modulus $(B)$ and shear modulus $(G)$. Bulk modulus $(B)$ and shear modulus $(G)$ are firstly calculated from the single-crystal elastic constants by VoigtReuss average scheme [35-37].

The calculated Debye temperatures and sound velocities of graphene/Cu composite materials are listed in Table 2. Generally, the addition of graphene significantly changes the Debye temperature of copper. The numerical values increase from $335 \mathrm{~K}$ (pure $\mathrm{Cu}$ ) to $564 \mathrm{~K}$
Table 2

The calculated Debye temperature $\left(\Theta_{D}, \mathrm{~K}\right)$, sound velocities (in $\mathrm{m} / \mathrm{s}$ ), density $\left(\mathrm{g} / \mathrm{cm}^{3}\right)$, bulk modulus (GPa) and shear modulus (GPa) of different models.

\begin{tabular}{llllllll}
\hline Phase & $\rho$ & $\mathrm{B}$ & $\mathrm{G}$ & $v_{t}$ & $v_{t}$ & $V_{m}$ & $\Theta_{D}$ \\
\hline Pure Cu & 8.93 & 137.4 & 46.3 & 4723 & 2277 & 2560 & $335[38]$ \\
Model a & 7.88 & 148.7 & 72.0 & 5573 & 3024 & 4181 & 564 \\
Model b & 7.79 & 133.1 & 65.3 & 5317 & 2896 & 3972 & 535 \\
Model c & 7.80 & 153.3 & 67.7 & 5587 & 2945 & 4058 & 546 \\
\hline
\end{tabular}

(Model a), $535 \mathrm{~K}$ (Model b) and $546 \mathrm{~K}$ (Model c). The disparity in the Debye temperature among graphene/copper composites is small, which is consistent with their structural characters above mentioned. Owning to higher Debye temperature, graphene/copper composites are supposed to be more thermodynamically stable and stronger bonding force between atoms compared to pure $\mathrm{Cu}$ [39].

\subsection{Stretching simulations}

Except the excellent electrical conductivity and thermodynamically stable favorable condition for graphene/copper composites, the mechanical stability is crucial to the feasibility of crystal existence. The criteria of mechanical stability could be evaluated by means of stretching simulations.

In our stretching calculations, the most stable graphene/copper structures (model a, b and c in Fig. 1) are taken as the starting configuration, and pure $\mathrm{Cu}$ is stretched as well to make a comparison. Then the uniaxial strains are carried out in certain axis direction $(\mathrm{x}-, \mathrm{y}-$ or $\mathrm{z}$ axes displayed in Fig. 1, where $\mathrm{x}$-, $\mathrm{y}$-axes represent parallel to graphene layer and z-axes represents vertical directions of graphene layer) step by step. On each of the step, all the atoms are allowed full freedom of motion until the system reaches the minimum energy, and every initial structure for next step is based on the pro-optimum structure.

For $\mathrm{x}$ and $\mathrm{y}$ directions, graphene/Cu systems get obvious strength enhancement, which are separately $174 \%$ and $162 \%$ enhancement over pure $\mathrm{Cu}$. Stretch along the $\mathrm{x}$ axis in Fig. 3 (a), for pure copper, ultimate tensile strength is $16.41 \mathrm{GPa}$ and the failure strain is $44 \%$. The ultimate tensile strength of model a, b and c are $28.48,28.49$ and $28.46 \mathrm{GPa}$ respectively and failure strains are $23 \%$. In Fig. 3 (b) stretch along the y axis, the ultimate tensile strength of pure $\mathrm{Cu}$ is $14.27 \mathrm{GPa}$ and the failure strain is $40 \%$. The ultimate tensile strength of model a, b and c are $26.43,26.66$ and $26.78 \mathrm{GPa}$ respectively and failure strains are $23 \%$. When composite materials are stretched parallel to the direction of graphene (in $\mathrm{x}-, \mathrm{y}$-axes), the $s p^{2}$ bonds in graphene begins to break at $21 \%$, as shown in Fig. 3(a) and (b). During tensile deformation, the rupture of $s p^{2}$ bonds will lead to the rupture of other bonds in another graphene layer and the copper layer, eventually result in the failure of the materials. Stress has a dramatic decrease in the stress-strain curve 

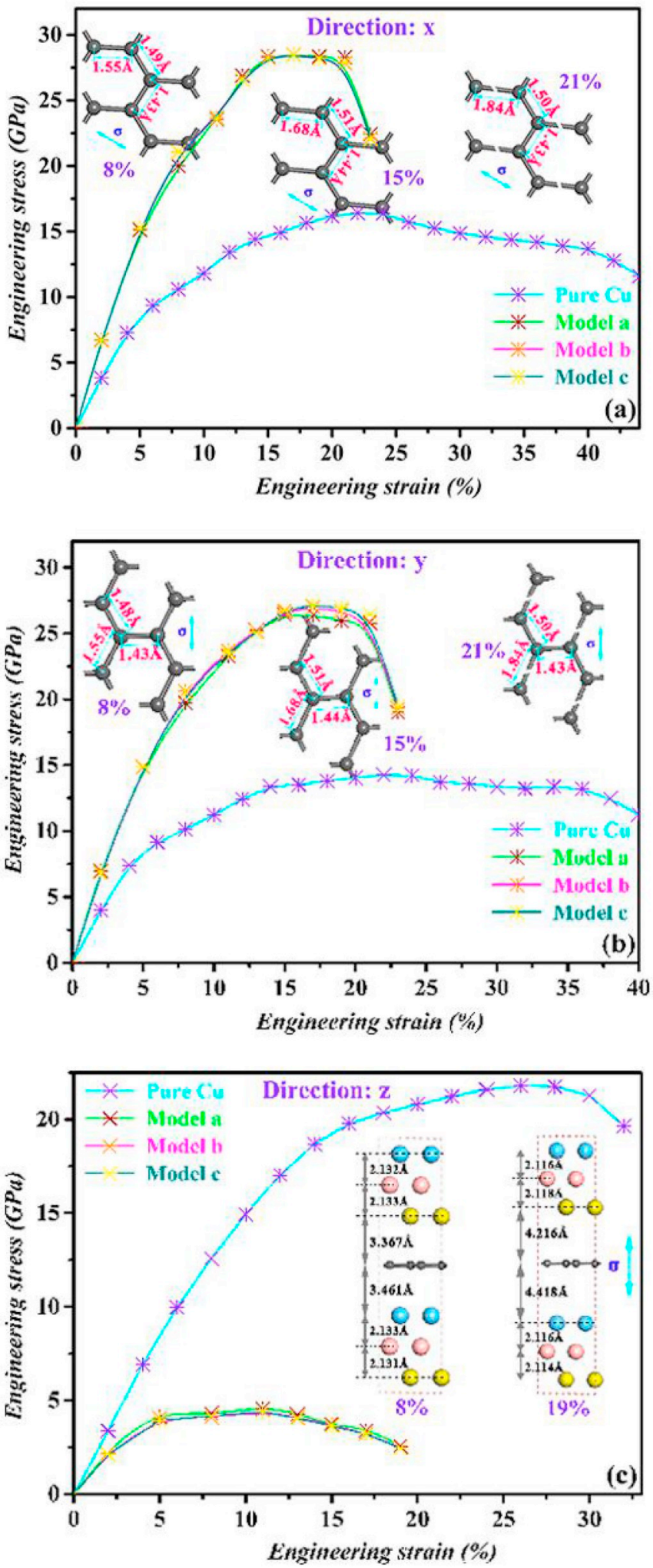

Fig. 3. Strain-stress curves for pure $\mathrm{Cu}$ and graphene/Cu systems in $\mathrm{x}(\mathrm{a}), \mathrm{y}(\mathrm{b})$, and $\mathrm{z}(\mathrm{c}$ ) axes directions (top views of graphene in model $\mathrm{c}$ at $8 \%, 15 \%$ and $21 \%$ tensile strains are shown as in sets, side views of model c under $8 \%$ and $19 \%$ strains are also shown as in sets; $\sigma$ and arrow indicate the direction of external stress).

as the $s p^{2}$ bonds are broken, which indicates that the tensile strength and fracture strain of the graphene/Cu composites are dominated by the $\mathrm{sp}^{2}$ bonds of the graphene $[18,40]$.
Stretch along the $\mathrm{z}$ axis, about pure $\mathrm{Cu}$, the ultimate tensile strength is $21.8 \mathrm{GPa}$ and the failure strain is $32 \%$. The ultimate tensile strength of model a, b and c are $4.55,4.42$ and $4.40 \mathrm{GPa}$, but materials is failure in a small amount of deformation, as shown in Fig. 3 (c). Finally, bulk modulus (B) and shear modulus (G) obtained for $\mathrm{Cu}$ and graphene/Cu systems calculated from the single-crystal elastic constants by VoigtReuss average scheme, where the Young's modulus (E) is estimated by this equation [37]:

$$
\mathrm{E}=\frac{9 \mathrm{~GB}}{\mathrm{G}+3 \mathrm{~B}}
$$

Bulk modulus are 137.4(pure $\mathrm{Cu}$ ), 148.7(model a), 133.1(model b) and 153.3(model c) GPa; shear modulus are 46.3(pure $\mathrm{Cu}$ ), 72.0(model a), 65.3(model b) and 67.7(model c) GPa; Young's modulus are 124.9(pure Cu), 186.1(model a), 168.4(model b), 176.9(model c) GPa. Apparently, graphene/Cu composites have better ability of deformation resistance than pure $\mathrm{Cu}$. Above results clearly show that the mechanical properties of graphene/Cu composites are greatly improved and graphene is a good reinforcing agent in the $\mathrm{Cu}$ matrix. Compared with pure $\mathrm{Cu}$, the mechanical enhancement in paralleled direction is mainly contributed to graphene layer with an outstanding mechanical property. In $\mathrm{z}$-axis direction (vertical direction of graphene layer), mechanical properties get decreased after inserting graphene, suggesting that graphene has a poor interfacial interactions with both sides of $\mathrm{Cu}$ [24]. In the future, the mechanical properties can be improved by improving the bonding ability of the interface.

\subsection{Mechanical properties analysis}

The tensile properties of model a, model b and model $\mathrm{c}$ in same drawing direction are almost identical, which shows that for graphene/ $\mathrm{Cu}$ composites, whose stacking ways has a small effect on mechanical properties. Consequently, we select model $\mathrm{c}$ as a representative to intensive study in terms of changes of charge, atomic position and generalized stacking fault energies to reveal the strengthening mechanism of graphene in composites.

\subsubsection{Change of magnitude of atomic charge during tensile process}

Change of magnitude of atomic charge is closely related to the interaction between atoms. Under different tensile strains, magnitude of atomic charge about model $\mathrm{c}$ at different layers has been counted, as shown in Table 3(charge means total charge of all the atoms in one layer). $C u_{i}, i=1,2,3,4,5$ and 6 , which represents the copper atoms in specified layers (for example, $\mathrm{Cu}_{1}$ represents the first layer of model $\mathrm{c}$ in which layer copper atoms also has a math numeric " 1 ", as shown in Fig. 4(a); Gr represents total charge of graphene transfer). For $\mathrm{x}$ and $\mathrm{y}$ directions, the magnitude of atomic charge in $\mathrm{Gr}, \mathrm{Cu}_{3}$ and $\mathrm{Cu}_{4}$ are increasing, while the other layers are almost unchanged. In $\mathrm{z}$-axes, the amount of charge in $\mathrm{Gr}$ is decreasing, while in $\mathrm{Cu}_{2}, \mathrm{Cu}_{3}, \mathrm{Cu}_{4}$ and $\mathrm{Cu}_{5}$ gradually increasing. The above results suggest that in parallel to the direction of graphene (in $\mathrm{x}-, \mathrm{y}$-axes), the interaction between graphene and adjacent copper atoms $\left(\mathrm{Cu}_{3}\right.$ and $\left.\mathrm{Cu}_{4}\right)$ became stronger, while in vertical directions of graphene layer (in z-axes), the interaction between interfaces is gradually diminished, and the interaction between the matrix copper atoms is becoming stronger.

\subsubsection{Images of atomic arrangements at different tensile strains}

To better understand the deformation process of graphene/Cu composites, different deformation images of atomic arrangements about model $\mathrm{c}$ as shown in Fig. 4. Fig. 4(a) and (b) show in $\mathrm{x}$-axes and $\mathrm{y}$ axes, the images of the atomic arrangements at $11 \%, 17 \%$ and $21 \%$ tensile strains. Stretching along x-axes, atoms slip along [101(-)] direction in a (111) plane; Stretching along y-axes, atoms slip along [11(-)0] direction in a (111) plane. As shown in Fig. 4(a) and (b), in the atomic glide direction, the copper atoms in $\mathrm{Cu}_{3}$ and $\mathrm{Cu}_{4}$ (dark yellow and dark blue) near the graphene has an obvious tendency to close to 
Table 3

Under different tensile strains, atomic charge of model c in different layers.

\begin{tabular}{|c|c|c|c|c|c|c|c|c|c|c|}
\hline \multirow[t]{2}{*}{ Phase } & \multirow[t]{2}{*}{ Species } & \multicolumn{9}{|l|}{ Charge (e) } \\
\hline & & Stain(\%) 0 & 5 & 8 & 11 & 13 & 15 & 17 & 19 & 21 \\
\hline \multirow[t]{7}{*}{ Model c-x } & $\mathrm{Cu}_{1}$ & 0.12 & 0.12 & 0.08 & 0.12 & 0.12 & 0.12 & 0.12 & 0.12 & 0.12 \\
\hline & $\mathrm{Cu}_{2}$ & 0.36 & 0.36 & 0.36 & 0.36 & 0.36 & 0.36 & 0.4 & 0.36 & 0.36 \\
\hline & $\mathrm{Cu}_{3}$ & 0 & 0.04 & 0.08 & 0.36 & 0.36 & 0.36 & 0.4 & 0.4 & 0.4 \\
\hline & $\mathrm{Gr}$ & -0.84 & -0.88 & -0.92 & -1.4 & -1.44 & -1.44 & -1.6 & -1.64 & -1.76 \\
\hline & $\mathrm{Cu}_{4}$ & -0.08 & -0.08 & -0.08 & 0.12 & 0.16 & 0.16 & 0.24 & 0.32 & 0.4 \\
\hline & $\mathrm{Cu}_{5}$ & 0.36 & 0.36 & 0.36 & 0.32 & 0.32 & 0.32 & 0.32 & 0.32 & 0.36 \\
\hline & $\mathrm{Cu}_{6}$ & 0.08 & 0.12 & 0.12 & 0.12 & 0.12 & 0.12 & 0.12 & 0.12 & 0.12 \\
\hline \multirow[t]{7}{*}{ Model c-y } & $\mathrm{Cu}_{1}$ & 0.12 & 0.12 & 0.12 & 0.12 & 0.12 & 0.12 & 0.12 & 0.12 & 0.12 \\
\hline & $\mathrm{Cu}_{2}$ & 0.36 & 0.32 & 0.32 & 0.36 & 0.36 & 0.36 & 0.36 & 0.36 & 0.36 \\
\hline & $\mathrm{Cu}_{3}$ & 0 & 0.04 & 0.12 & 0.4 & 0.4 & 0.36 & 0.36 & 0.4 & 0.4 \\
\hline & $\mathrm{Gr}$ & -0.84 & -0.88 & -0.96 & -1.44 & -1.44 & -1.48 & -1.64 & -1.64 & -1.76 \\
\hline & $\mathrm{Cu} 4$ & -0.08 & -0.08 & -0.08 & 0.12 & 0.12 & 0.2 & 0.24 & 0.32 & 0.4 \\
\hline & $\mathrm{Cu}_{5}$ & 0.36 & 0.36 & 0.36 & 0.32 & 0.32 & 0.32 & 0.32 & 0.32 & 0.36 \\
\hline & $\mathrm{Cu}_{6}$ & 0.08 & 0.12 & 0.12 & 0.12 & 0.12 & 0.12 & 0.24 & 0.12 & 0.12 \\
\hline \multirow[t]{7}{*}{ Model c-z } & $\mathrm{Cu}_{1}$ & 0.12 & 0.08 & 0.08 & 0.08 & 0.08 & 0.04 & 0.04 & 0.04 & - \\
\hline & $\mathrm{Cu}_{2}$ & 0.36 & 0.4 & 0.44 & 0.48 & 0.52 & 0.52 & 0.56 & 0.56 & - \\
\hline & $\mathrm{Cu}_{3}$ & 0 & -0.16 & -0.24 & -0.32 & -0.36 & -0.4 & -0.44 & -0.48 & - \\
\hline & $\mathrm{Gr}$ & -0.84 & -0.68 & -0.60 & -0.52 & -0.48 & -0.4 & -0.4 & -0.36 & - \\
\hline & $\mathrm{Cu}_{4}$ & -0.08 & -0.12 & -0.2 & -0.28 & -0.32 & -0.36 & -0.36 & -0.4 & - \\
\hline & $\mathrm{Cu}_{5}$ & 0.36 & 0.4 & 0.44 & 0.48 & 0.48 & 0.52 & 0.52 & 0.56 & - \\
\hline & $\mathrm{Cu}_{6}$ & 0.08 & 0.08 & 0.08 & 0.08 & 0.08 & 0.08 & 0.08 & 0.08 & - \\
\hline
\end{tabular}

each other compared with copper atoms in $\mathrm{Cu}_{1}$ and $\mathrm{Cu}_{6}$ (light yellow and light blue, which sit over same carbon atoms as $\mathrm{Cu}_{3}$ and $\mathrm{Cu}_{4}$ ). It demonstrates that graphene could effectively prevent cracks initiation and improve the mechanical properties of the materials. These change of laws are the same as model a and model b.

\subsubsection{Parallel to graphene layer, displacement change of atoms in different layers}

In order to further understand the effect of graphene in parallel to graphene layer direction, displacement change of different layers of atoms is discussed, as shown in Table 4. Throughout the study process, we find copper atoms in same layer have the same atomic displacement change, and the change rule of nonequivalent carbon atoms are inconsistent, other carbon atoms consistent with them. We select one copper atom in each layer and two nonequivalent carbon atoms to study their displacement change. Research indicates that the change of atomic displacement in the same layer is exactly the same, yet the variation of displacement in different layers has a big disparity, which indicating that the tensile deformation of the composites are carried out in a layer, that is to say, deformation of composites is achieved by means of the slip deformation between layer to layer.

In Table $4, \Delta \mathrm{X}$ and $\Delta \mathrm{Y}$ represent the differences between the atomic fractional coordinates of $21 \%$ and $0 \%$ separately. The displacement change of the copper atoms $\left(\mathrm{Cu}_{3}\right.$ and $\left.\mathrm{Cu}_{4}\right)$ near the graphene is larger. However, the shift/displacement change of copper atoms far away from
Table 4

Stretching along $\mathrm{x}$ - or $\mathrm{y}$-axis, atomic displacement change in different layers of model c.

\begin{tabular}{lllll}
\hline \multirow{2}{*}{ Layer } & \multicolumn{3}{c}{$\mathrm{x}$-axis } & \multicolumn{3}{l}{$\mathrm{y}$-axis } \\
\cline { 2 - 5 } & $\Delta \mathrm{X}$ & $\Delta \mathrm{Y}$ & $\Delta \mathrm{X}$ & $\Delta \mathrm{Y}$ \\
\hline $\mathrm{Cu}_{1}$ & 0.02 & 0.026 & -0.022 & -0.035 \\
$\mathrm{Cu}_{2}$ & -0.012 & -0.006 & 0.011 & -0.001 \\
$\mathrm{Cu}_{3}$ & -0.046 & -0.047 & 0.054 & 0.035 \\
$\mathrm{C}_{1}$ & 0.108 & 0.137 & 0.124 & 0.09 \\
$\mathrm{C}_{2}$ & 0.125 & 0.138 & 0.124 & 0.108 \\
$\mathrm{Cu}_{4}$ & 0.128 & 0.151 & -0.147 & -0.143 \\
$\mathrm{Cu}_{5}$ & 0.089 & 0.095 & -0.091 & -0.104 \\
$\mathrm{Cu}_{6}$ & 0.054 & 0.056 & -0.053 & -0.069 \\
\hline
\end{tabular}

graphene has a tendency to decrease. Graphene plays a great influence on tensile deformation. In the process of deformation, stress concentration can be delayed effectively because of stress transfer from graphene to matrix through the atomic displacement. Reducing the stress concentration could achieve good plasticity of composites. Meanwhile, strengthening mechanism could result from deformation hardening from graphene and adjacent copper atoms. It should be noted that the effects of graphene from the present calculation is in good agreement with similar observations in the experiment which state that strengthening effect of graphene/ $\mathrm{Cu}$ composites is

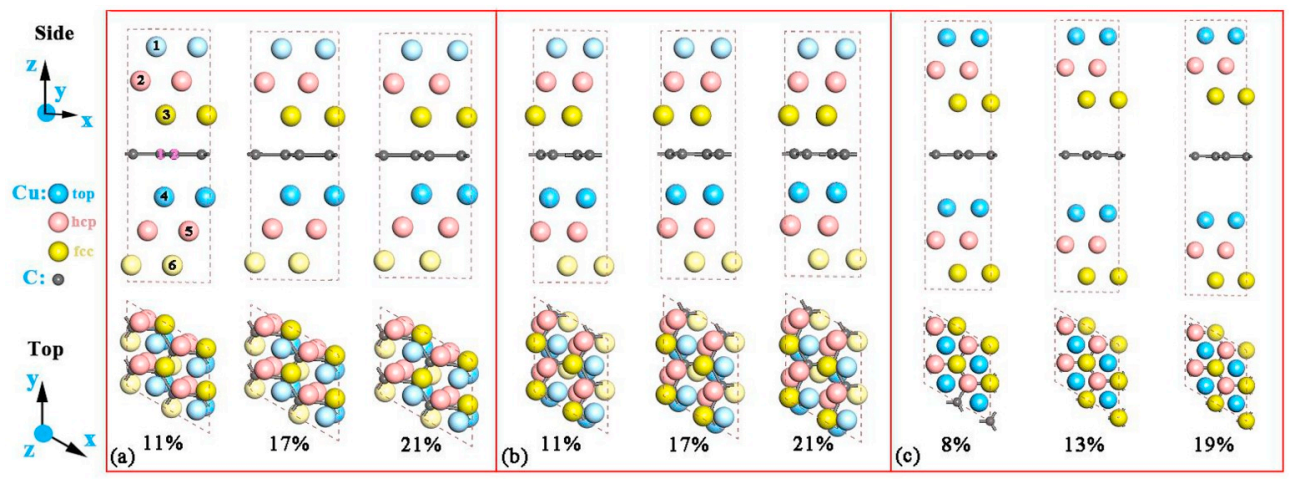

Fig. 4. atomic configuration images of model $\mathrm{c}$ at various strains in $\mathrm{x}(\mathrm{a}), \mathrm{y}(\mathrm{b})$, and $\mathrm{z}$ (c) axes directions. 


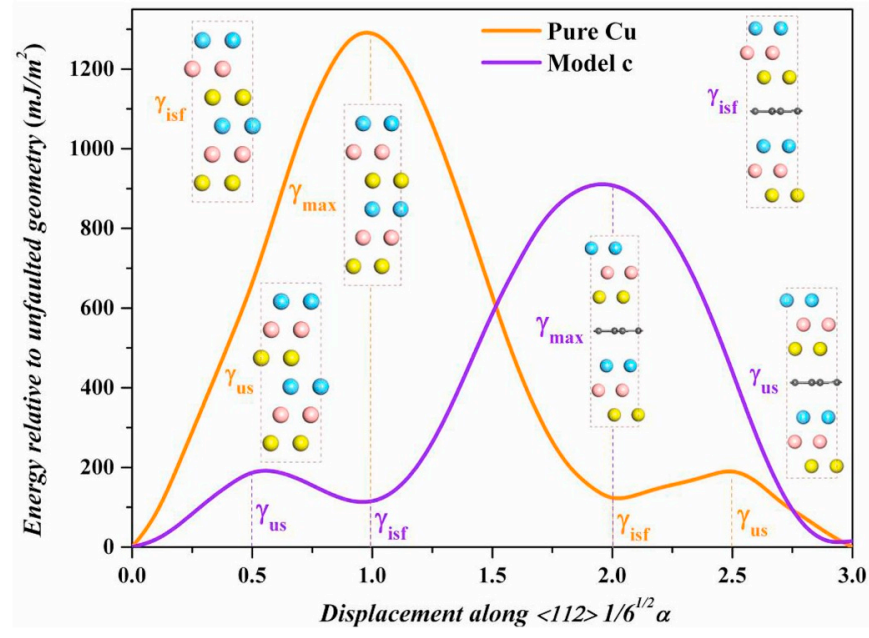

Fig. 5. GSFE curves of pure $\mathrm{Cu}$ and model c slipping along (111)/ $<112>$ direction, the displacements are in units of their Burgers vectors $b_{p}$, and a represents the lattice constant (illustrations are models slipping different displacement).

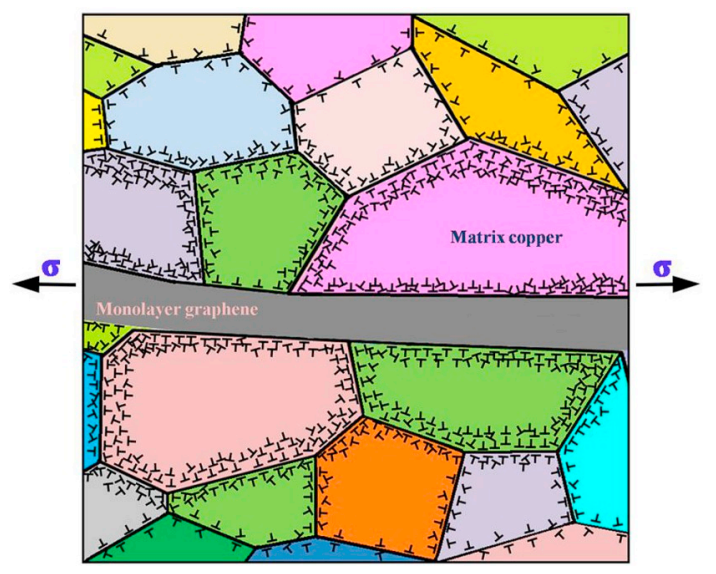

Fig. 6. The schematic illustration of the distribution of stress under specific deformation.

contributed to load transfer [15].

\subsubsection{Effect of graphene on stacking fault energy of pure $\mathrm{Cu}$}

To validate the aforementioned results, the effect of graphene on stacking fault energy of $\mathrm{Cu}$ is investigated. The generalized stacking fault energies (GSFE) could be derived as follows [41]:

$\gamma=\frac{E_{\mathrm{r}}-E_{0}}{A}$

where $E_{r}$ is the total energy of the model after the slip of the displacement $(r)$ along the Burgers vector $(\mathrm{a} / 6<112>), E_{0}$ is the total energy of the model before the slip, and $A$ is the area of the surface. Consequently, the generalized-stacking-fault-energy (GSFE) curve for pure $\mathrm{Cu}$ and model $\mathrm{c}$ have been successfully calculated by rigidly shearing at a ( 1111 ) plane along a $<112>$ slip direction, as shown in Fig. 5. Unstable stacking fault energy $\left(\gamma_{u s}\right)$ is used to represent the energy barrier of the dislocation emission [42]. Values of $\gamma_{u s}$ about pure $\mathrm{Cu}$ and model $\mathrm{c}$ from the present study are $197 \mathrm{~mJ} / \mathrm{m}^{2}$ and $193 \mathrm{~mJ} / \mathrm{m}^{2}$ respectively. The present study of pure $\mathrm{Cu}$ is consistent with the $\gamma_{u s}$ values $\left(180 \mathrm{~mJ} / \mathrm{m}^{2}\right)$ from first principles calculation $[43,44]$. The addition of graphene in $\mathrm{Cu}$ would increase the width of extended dislocations and facilitate the slip of the dislocation [45].

It is of importance to further find out the effects of graphene on the ductility of $\mathrm{Cu}$. Specifically, the ductility parameter (D) could be expressed by the following equation $[45,46]$.

$\mathrm{D}=\frac{0.3 \gamma_{s}}{\gamma_{u s}}$

Where is the unstable stacking fault energy, $\gamma_{s}$ is the surface energy can be calculated as below [47]:

$\gamma_{s}=\frac{E_{\text {slab_ } n} n E_{\text {bulk }}}{2 A}$

Where $E_{\text {slab }}$ and $E_{\text {bulk }}$ represent for the total energy of the constructed slab model and bulk model, respectively, and $A$ is the area of the slab model. It should be pointed out that the calculated surface energies of pure $\mathrm{Cu}$ and model $\mathrm{c}$ are 1.87 and $3.24 \mathrm{~J} / \mathrm{m}^{2}$. The present study of pure $\mathrm{Cu}$ is consistent with the $\gamma_{s}$ values $\left(1.83 \mathrm{~J} / \mathrm{m}^{2}\right)$ from experiment [48]. Ductility parameter (D) of pure $\mathrm{Cu}$ and model $\mathrm{c}$ are greater than 1 , implying that they are plastic materials. Graphene considered here to show a tendency to decrease both the unstable fault energy and intrinsic fault energy for the current slip system, which makes the dislocation of glide easier and slow the stress concentration. As shown in Fig. 6, the copper atoms adjacent to graphene have a large amount of deformation and transfer the stress to the distance. Generally, graphene/copper systems are expected to show superior strength due to strain strengthening meanwhile maintaining good ductility during the load transfer.

\section{Conclusion}

In this work, the structure and interface stability, electrical conductivity, Debey temperature and mechanical properties of graphene/ $\mathrm{Cu}$ composite materials are systematically investigated by the first principles calculation. Compared with pure $\mathrm{Cu}$, composites undergo excellent electrical conductivity, Debye temperature increase from $335 \mathrm{~K}$ (pure $\mathrm{Cu}$ ) to $564 \mathrm{~K}$ (Model a), $535 \mathrm{~K}$ (Model b) and $546 \mathrm{~K}$ (Model c). Young's modulus, shear modulus and bulk modulus are significant improved. The following conclusions could be achieved. Parallel to the graphene, the interaction between graphene and adjacent copper atoms $\left(\mathrm{Cu}_{3}\right.$ and $\left.\mathrm{Cu}_{4}\right)$ became stronger with the increase of strain and when the strain is too high it broke due to the failure of the $\mathrm{sp}^{2}$ bonds of graphene. Besides, graphene could effectively prevent crack's initiation and growth due to stress transfer between atoms. Deformation strengthening improves the strength of composites. Perpendicular to the graphene, the interaction between interfaces is diminished quickly due to weak force between graphene and copper atoms. In practical application, making graphene's parallel grow in copper to prepare the layered structure through which we could obtain composites with eminent comprehensive properties.

\section{Acknowledgements}

This work was supported by the National Natural Science Foundation of China (No. 51371123), the Natural Science Foundation of Shanxi Province (No. 201601D202033, 201601D202034), and the Innovation Project of Shanxi Graduate Education (No. 2016JD20).

\section{References}

[1] Z.A. Ghaleb, M. Mariatti, Z.M. Ariff, Properties of graphene nanopowder and multiwalled carbon nanotube-filled epoxy thin-film nanocomposites for electronic applications: the effect of sonication time and filler loading, Compos. Part. A-Appl. S. 58 (3) (2014) 77-83.

[2] X. Fuku, K. Kaviyarasu, N. Matinise, M. Maaza, Punicalagin green functionalized $\mathrm{Cu} / \mathrm{Cu}_{2} \mathrm{O} / \mathrm{ZnO} / \mathrm{CuO}$ nanocomposite for potential electrochemical transducer and catalyst, Nanoscale Research Letters 11 (1) (2016) 386.

[3] D. Orlov, H. Fujiwara, K. Ameyama, Obtaining copper with harmonic structure for the optimal balance of structure-performance relationship, Mater. Trans. 54 (2013) 1549-1553.

[4] S. Hashimoto, Dislocation structures and crystal orientations of copper single crystals deformed by equal-channel angular pressing, Mater. Sci. Eng. 405 (1-2) (2005) 221-232. 
[5] T.H. Fang, W.L. Li, N.R. Tao, K. Lu, Revealing extraordinary intrinsic tensile plasticity in gradient nano-grained copper, Science 331 (2011) 1587-1590.

[6] Q. Zhang, Y.S. Liu, Y.H. Ren, Y.X. Wu, Z.P. Gao, et al., Enhanced tensile ductility and strength of electrodeposited ultrafine-grained nickel with a desired bimodal microstructure, Mater. Sci. Eng. 701 (2017) 196-202.

[7] S.F. Bartolucci, J. Paras, M.A. Rafiee, J. Rafiee, S. Lee, D. Kapoor, et al, Graphene-aluminum nanocomposites, Mater. Sci. Eng. 528 (27) (2011) 7933-7937.

[8] X.J. Long, B. Li, L. Wang, J.Y. Huang, J. Zhu, S.N. Luo, Shock response of Cu/ graphene nanolayered composites, Carbon 103 (2016) 457-463.

[9] Y.P. Ren, G.X. Cao, Effect of geometrical defects on the tensile properties of graphene, Carbon 103 (2016) 125-133.

[10] C. Soldano, A. Mahmood, E. Dujardin, Production, properties and potential of graphene, Carbon 48 (8) (2010) 2127-2150.

[11] X. Gao, H.Y. Yue, E.J. Guo, H. Zhang, X.Y. Lin, L.H. Yao, et al., Mechanical properties and thermal conductivity of graphene reinforced copper matrix composites, Powder Technol. 301 (2016) 601-607.

[12] S.W. Feng, Q. Guo, Z. Li, G.L. Fan, Z.Q. Li, D.B. Xiong, et al., Strengthening and toughening mechanisms in graphene-Al nanolaminated composite micro-pillars, Acta, Materials 125 (2017) 98-108.

[13] L.D. Wang, Z.Y. Yang, Y. Cui, B. Wei, S.C. Xu, J. Sheng, et al., Graphene-copper composite with micro-layered grains and ultrahigh strength, Sci. Rep. 7 (2017) 41896.

[14] R.R. Jiang, X.F. Zhou, Q. Fang, Z.P. Liu, Copper-graphene bulk composites with homogeneous graphene dispersion and enhanced mechanical properties, Mater. Sci. Eng. 654 (2016) 124-130.

[15] Y.K. Chen, X. Zhang, E.Z. Liu, C.N. He, C.S. Shi, J.J. Li, et al., Fabrication of in-situ grown graphene reinforced Cu matrix composites, Sci. Rep. 6 (2016) 19363.

[16] K. Kaviyarasu, E. Manikandan, J. Kennedy, M. Maaza, Synthesis and analytical applications of photoluminescent carbon nanosheet by exfoliation of graphite oxide without purification, J. Mater. Sci. Mater. Electron. 27 (12) (2016) 13080-13085.

[17] K. Kaviyarasu, C.M. Magdalane, E. Manikandan, M. Jayachandran, R. Ladchumananandasivam, S. Neelamani, et al., Well-aligned graphene oxide nanosheets decorated with zinc oxide nanocrystals for high performance photocatalytic application, Int. J. Nanomed. 14 (03) (2015) 1550007.

[18] K. Duan, F.D. Zhu, K. Tang, L.P. He, Y.M. Chen, S. Liu, Effects of chirality and number of graphene layers on the mechanical properties of graphene-embedded copper nanocomposites, Comput. Mater. Sci. 117 (2016) 294-299.

[19] Y.Z. He, F. Huang, H. Li, Y.W. Sui, F.X. Wei, Q.K. Meng, et al., Tensile mechanical properties of nano-layered copper/graphene composite, Physica E 87 (2017) 233-236.

[20] X.Y. Liu, F.C. Wang, W.Q. Wang, H.A. Wu, Interfacial strengthening and self-healing effect in graphene-copper nanolayered composites under shear deformation, Carbon 107 (2016) 680-688.

[21] J.P. Perdew, K. Burke, M. Ernzerhof, Generalized gradient approximation made simple, Phys. Rev. Lett. 77 (18) (1996) 3865.

[22] B. Mortazavi, O. Rahaman, M. Makaremi, A. Dianatc, G. Cunibertic, T. Rabcz- ukd, First-principles investigation of mechanical properties of silicene, germanene and stanene, Physica E 87 (2016) 228-232.

[23] S. Grimme, Semiempirical GGA-type density functional constructed with a longrange dispersion correction, J. Comput. Chem. 27 (15) (2006) 1787.

[24] J. Avila, I. Razado, S. Lorcy, R. Fleurier, E. Pichonat, D. Vignaud, et al., Exploring electronic structure of one-atom thick polycrystalline graphene films: a nano angle resolved photoemission study, Sci. Rep. 3.8 (2013) 02439.

[25] T. Frank, M. Gmitra, J. Fabian, Theory of electronic and spin-orbit proximity effects in graphene on Cu(111), Phys. Rev. B 93 (15) (2016) 1-8.

[26] P.A. Khomyakov, G. Giovannetti, P.C. Rusu, G. Brocks, J. van den Brink, P.J. Kelly, First-principles study of the interaction and charge transfer between graphene and metals, Phys. Rev. B 79 (19) (2009) 195425.

[27] E.S. Souza, W.L. Scopel, R.H. Miwa, Switchable magnetic moment in cobalt-doped graphene bilayer on Cu(111): an ab initio study, Phys. Rev. B 93 (23) (2016) 235308.

[28] P.A. Khomyakov, G. Giovannetti, P.C. Rusu, G. Brocks, J. van den Brink, P.J. Kelly, First-principles study of the interaction and charge transfer between graphene and metals, Phys. Rev. B 79 (2009) 195425.

[29] N. Dong, Y.F. Qiao, C.L. Zhang, J. Wang, G.W. Fan, X.D. Fang, et al., Combined experiment and first-principles study of the formation of the Al2O3 layer in alumina-forming austenitic stainless steel, RSC Adv. 7 (26) (2017) 15727-15734.

[30] D.J. Siegel, L.G.H. Jr, J.B. Adams, Adhesion, stability, and bonding at metal/metalcarbide interfaces: Al/WC, Surf. Sci. 498 (3) (2002) 321-336.

[31] R. D'Souza, S. Mukherjee, First-principles study of the electrical and lattice thermal transport in monolayer and bilayer graphene, Phys. Rev. B 95 (2017) 085435.

[32] M.B. Kanoun, S. Goumri-Said, A.H. Reshak, Theoretical study of mechanical, electronic, chemical bonding and optical properties of $\mathrm{Ti}_{2} \mathrm{SnC}, \mathrm{Zr}_{2} \mathrm{SnC}, \mathrm{Hf}_{2} \mathrm{SnC}$ and Nb2SnC, Comput. Mater. Sci. 47 (2) (2009) 491-500.

[33] O.L. Anderson, A simplified method for calculating the Debye temperature from elastic constants, J. Phys. Chem. Solid. 24 (7) (1963) 909-917.

[34] E. Schreiber, O. Anderson, N. Soga, Elastic Constants and Their Measurements, McGraw Hill, New York, 1973.

[35] W. Voigt, Lehrburch der Kristallphysik, Teubner, Leipzig, 1928.

[36] A. Reuss, Berechnung der Fließgrenze von Mischkristallen auf Grund der Plastizitätsbedingung für Einkristalle, Z. Angew. Math. Mech. 9 (1) (1929) 49-58.

[37] Z.J. Wu, E.J. Zhao, H.P. Xiang, X.F. Hao, X.J. Liu, M. Jian, Crystal structures and elastic properties of superhard $\operatorname{IrN}_{2}$ and $\mathrm{IrN}_{3}$ from first principles, Phys. Rev. B 76 (5) (2007) 054115.

[38] Y.D. Zhu, M.F. Yan, Y.X. Zhang, C.S. Zhang, First-principles investigation of structural, mechanical and electronic properties for $\mathrm{Cu}-\mathrm{Ti}$ intermetallics, Comput. Mater. Sci. 123 (2016) 70-78.

[39] Y.H. Duan, B. Huang, Y. Sun, M.J. Peng, S.G. Zhou, Stability, elastic properties and electronic structures of the stable $\mathrm{Zr}-\mathrm{Al}$ intermetallic compounds: a first principles investigation, J. Alloy. Comp. 590 (2014) 50-60.

[40] T.H. Liu, C.W. Pao, C.C. Chang, Effects of dislocation densities and distributions on graphene grain boundary failure strengths from atomistic simulations, Carbon 50 (10) (2012) 3465-3472.

[41] Q. Jing, C.Y. Wu, J.L. Fan, H.R. Gong, Effect of alloying elements on stacking fault energy and ductility of tungsten, J. Alloy. Comp. 737 (2018) 372-376.

[42] J.R. Rice, Dislocation nucleation from a crack tip: an analysis based on the Peierls concept, J. Mech. Phys. Solid. 40 (2) (1992) 239-271.

[43] S. Kibey, J.B. Liu, D.D. Johnson, H. Sehitoglu, Predicting twinning stress in fcc metals: linking twin-energy pathways to twin nucleation, Acta Mater. 55 (20) (2007) 6843-6851.

[44] M. Jahnátek, J. Hafner, M. Krajčí, Shear deformation, ideal strength, and stacking fault formation of fcc metals: a density-functional study of $\mathrm{Al}$ and $\mathrm{Cu}$, Phys. Rev. B Condens. Matter 79 (22) (2009) 1377-1381.

[45] J. Zhang, G. Liu, X. Wei, Strengthening and ductilization potentials of nonmetallic solutes in magnesium: first-principles calculation of generalized stacking fault energies, Mater. Lett. 150 (2015) 111-113.

[46] S.X. Shi, L.G. Zhu, H. Zhang, Z.M. Sun, Strength and ductility of niobium alloys with nonmetallic elements: a first-principles study, Mater. Lett. 189 (15) (2017) $310-312$.

[47] L. Sun, X.F. Chen, W.C. Yu, H.G. Sun, X. Zhao, X.G. Xu, et al., The effect of the surface energy and structure of the $\mathrm{SiC}$ substrate on epitaxial graphene growth, RSC Adv. 6 (103) (2016) 100908-100915.

[48] F.R. de Boer, R. Boom, W.C.M. Mattens, A.R. Miedema, A.K. Niessen, Cohesion in Metals: Transition Metal Alloys, North-Holland, Amsterdam, 1989. 